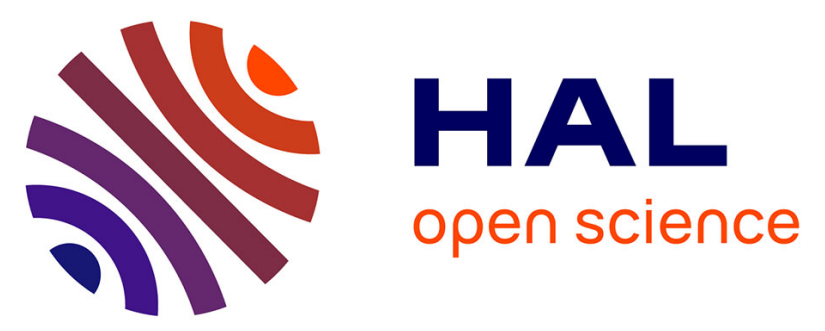

\title{
Thermo-mechanical behaviour of flax/green epoxy composites: Evaluation of thermal expansion coefficients and application to internal stress calculation
}

El Hadi Saidane, Daniel Scida, Rezak Ayad

\section{- To cite this version:}

El Hadi Saidane, Daniel Scida, Rezak Ayad. Thermo-mechanical behaviour of flax/green epoxy composites: Evaluation of thermal expansion coefficients and application to internal stress calculation. Industrial Crops and Products, 2021, 170, pp.113786. 10.1016/j.indcrop.2021.113786 . hal-03285392

HAL Id: hal-03285392

https://hal.univ-reims.fr/hal-03285392

Submitted on 21 Jul 2021

HAL is a multi-disciplinary open access archive for the deposit and dissemination of scientific research documents, whether they are published or not. The documents may come from teaching and research institutions in France or abroad, or from public or private research centers.
L'archive ouverte pluridisciplinaire $\mathbf{H A L}$, est destinée au dépôt et à la diffusion de documents scientifiques de niveau recherche, publiés ou non, émanant des établissements d'enseignement et de recherche français ou étrangers, des laboratoires publics ou privés.

$$
\text { Copyright }
$$


archives-ouvertes

\section{Thermo-mechanical behaviour of flax/green epoxy composites: Evaluation of thermal expansion coefficients and application to internal stress calculation}

El Hadi Saidane, Daniel Scida, Rezak Ayad

\section{To cite this version:}

El Hadi Saidane, Daniel Scida, Rezak Ayad. Thermo-mechanical behaviour of flax/green epoxy composites: Evaluation of thermal expansion coefficients and application to internal stress calculation. Industrial Crops and Products, Elsevier, 2021, 170, pp.113786. 10.1016/j.indcrop.2021.113786 . hal03285392

HAL Id: hal-03285392

https://hal.univ-reims.fr/hal-03285392

Submitted on 21 Jul 2021

HAL is a multi-disciplinary open access archive for the deposit and dissemination of scientific research documents, whether they are published or not. The documents may come from teaching and research institutions in France or abroad, or from public or private research centers.
L'archive ouverte pluridisciplinaire HAL, est destinée au dépôt et à la diffusion de documents scientifiques de niveau recherche, publiés ou non, émanant des établissements d'enseignement et de recherche français ou étrangers, des laboratoires publics ou privés. 


\title{
Thermo-mechanical behaviour of flax/green epoxy composites: Evaluation of thermal expansion coefficients and application to internal stress calculation
}

\author{
El Hadi Saidane ${ }^{\mathrm{a}, *}$, Daniel Scida ${ }^{\mathrm{b}}$, Rezak Ayad ${ }^{\mathrm{b}}$ \\ a Université de Haute Alsace, Laboratoire de Physique et Mécanique Textiles EA 4365, 68093, Mulhouse, France \\ ${ }^{\mathrm{b}}$ Université de Reims Champagne Ardenne, ITheMM EA 7548, 51097, Reims, France
}

\section{A R T I C L E I N F O}

\section{Keywords:}

Natural fibre composites

Flax fibres

Thermal expansion coefficient

Internal stresses

\begin{abstract}
A B S T R A C T
This work aims at evaluating the coefficients of linear thermal expansion (CLTE) of flax/green epoxy unidirectional composites and the CLTE of flax fibre. This required using high precision measuring instrument to experimentally evaluate the CLTE of unidirectional composites with various fibre contents. The flax fibre CLTE were first estimated using an inverse approach with two micromechanical models. From the longitudinal and transverse CLTE, the internal stresses of various symmetric and antisymmetric laminates, due to temperature variation, were then predicted by a 2D analytical model based on classical laminate theory. The inverse approach results showed that the transverse CLTE of flax fibre was positive and estimated at $75 \pm 5 \times 10^{-6} / \mathrm{K}$ whereas the longitudinal CLTE was negative and equal to $-1.2 \pm 0.1 \times 10^{-6} / \mathrm{K}$, highlighting the high anisotropy of flax fibres. The internal stress analysis in flax fibre laminates showed that the stacking sequence had a significant effect on the internal stresses, whatever the temperature variation. Regarding stacking the layers, choosing symmetric cross-ply laminate was more interesting than antisymmetric one for minimising the internal stresses. The normal stresses reached their maximum absolute values for the cross-ply laminates, whereas the maximum shear stress occurred in the $[0 / 60]_{\mathrm{s}}$ and $[0 / 60 / 0 / 60]$ stacking. This study highlighted the importance of choosing an optimised stacking sequence, such as the $0 / 30^{\circ}$ oriented laminates, and a relevant curing cycle prior to the manufacturing process, in order to obtain flax fibre laminates with low internal stresses.
\end{abstract}

\section{Introduction}

Because of the increasing ecological awareness and regulations to reduce $\mathrm{CO} 2$ emissions, the development of composites made from natural fibres has attracted considerable interest (Madhu et al., 2019). The use of natural fibres as reinforcement of polymer materials has gained popularity for different engineering applications (Karthi et al., 2019; Kim and Chalivendra, 2020). Among various natural fibres, flax is now becoming a suitable choice that could replace glass fibres as reinforcement of composites thanks to its good tensile properties (Goudenhooft et al., 2017; Lefeuvre et al., 2013). Besides the environmental benefits, compared to glass fibres, flax fibres have more advantages due to their high tensile mechanical properties combined with low density, low cost per weight and biodegradable characteristics (Amiri et al., 2017; Baley et al., 2021; Ramesh et al., 2017).

So far, many research studies for example on the mechanical and ageing characterisation of flax fibres are well reported by numerous au- thors (Abida et al., 2019; Cadu et al., 2019; Chilali et al., 2018b; Gager et al., 2019; Saidane et al., 2016b; Van Schoors et al., 2021). However, in spite of this current knowledge, there is little information about the transverse and longitudinal coefficients of linear thermal expansion (CLTE) of flax fibres and their reinforced composites. Their values are required, for example, to estimate the internal stresses generated during the manufacturing process of flax-fibre composites or the mechanical behaviour of flax-fibre composites in a temperature variable environment. In the first example, these stresses could occur between the manufacturing and post-cooling of the composites as the temperature changed from a relatively high manufacturing temperature to the service temperature.

Indeed, the presence of internal stresses in the composite laminates could influence the mechanical properties and the durability of the final structure. In within this context that many works have focused on the estimation of internal stresses in synthetic fibre-reinforced polymer composites by using experimental or numerical approaches (Asghari et

\footnotetext{
* Corresponding author.

E-mail address: el-hadi.saidane@uha.fr (E.H. Saidane).
} 
al., 2019; Dai et al., 2019; Gong et al., 2015; Magnier et al., 2021; Parlevliet et al., 2007a, 2007b, 2006). For instance, Gong et al. (Gong et al., 2015) used the incremental hole drilling method to determine the residual stresses in carbon fibre-reinforced epoxy (CFRP) composite laminates, combined with numerical modelling to calibrate coefficients. From several configurations of $\left[0_{2} / \theta_{2}\right]_{s}$ laminates, several findings were established: i) the residual stresses within the layers of the same orientation were approximately unchanging, ii) the residual stresses were highest in the $\left[0_{2} / 90_{2}\right]_{s}$ laminate compared to other types of laminates and iii) for the $\left[0_{2} / \theta_{2}\right]_{s}$ laminate, the residual stresses as a function of the angle $\theta$ were almost linear. In a study of Magnier et al. (Magnier et al., 2021), the residual stresses on unidirectional CFRP composites with different layers were experimentally measured by introducing new orthotropic formalism for the incremental hole drilling method. The reliability of the method used was demonstrated and it could be used for laminates made of complex layer stacking sequences. Despite these numerous works for traditional composites, few papers dealt with the estimation of thermal and hygroscopic internal stresses in natural fibre-reinforced composite laminates (Chilali et al., 2018a; Djellouli et al., 2021; Péron et al., 2020, 2019). As an example, Péron et al. (Péron et al., 2020) investigated the hygroscopic internal stresses by exposing asymmetric flax fibre-reinforced polypropylene laminates to various relative humidity conditions. They adopted an experimental and modelling strategy in order to estimate the internal stresses distribution through the laminate thickness. First of all, they observed that the composite laminates exposed to $0 \% \mathrm{RH}$ (Relative Humidity) exhibited the higher internal stresses compared to those stored in a $50 \% \mathrm{RH}$ condition. Then, they underlined that the stresses intensity was reduced by the progressive humidification due to the lower hygro-mechanical gradients.

Furthermore, after manufacturing of composite laminates, internal stresses arose due the temperature variation between the high processing temperature and the service temperature. This led to a higher shrinkage of the polymer matrix compared to the fibres that intensified the presence of internal stresses. These phenomena became more complex when the fibres did not have an isotropic behaviour, such as flax fibre. In this work, the thermo-mechanical behaviour of unidirectional (UD) flax fibre-reinforced green epoxy composites with several fibre volume fractions was investigated. First, the CLTE of UD composites was evaluated according to the ASTM D6341 and E831 standards. Due to their anisotropic structure, flax fibre UD composites were characterised by two independent CLTE, longitudinal along the fibre axis and transverse normal to this axis. The characterization approach was made by taking length measurements with a three-dimensional measuring machine (TMM) at three discrete temperatures. The longitudinal and transverse CLTE of flax fibre were then estimated from an inverse approach by using two micromechanical models. It was required to use an optimisation program based on the minimisation of the quadratic error, described in (Saidane et al., 2016b). Finally, the internal stresses induced by the thermal expansion were estimated in a symmetric and antisymmetric cross-ply laminates $\left([0 / 90]_{s}\right.$ and [0/90/0/90], respectively) by a $2 \mathrm{D}$ analytical model based on classical laminate theory. The thermo-mechanical behaviour of the composites was governed by a linear elastic constitutive law taking into account the expansion strains induced by thermal effects. Finally, the effect of the temperature variation and the stacking sequence on the internal stresses was studied. Note that in the following we will refer to internal stresses as stresses only induced thermally in the composite resulting from a temperature variation.

\section{Materials and methods}

\subsection{Materials and composites fabrication}

Untreated quasi-UD flax-fibre fabric (Depestele Group) with an areal weight $\mathrm{W}=200 \mathrm{~g} / \mathrm{m}^{2}$ was used in this study. Corresponding weft and warp ratio was $9 / 91$ by weight. The flax fibres were bonded together by a specific binder to form a flat roving, of which the linear mass was 500 Tex. According to the supplier, the flax fibre density $\rho_{f}$ was equal to $1450 \mathrm{~kg} / \mathrm{m}^{3}$. Note that flax yarns in the weft direction were removed to obtain UD fabrics. The thermoset matrix used to produce the composites was a green epoxy resin (SR GP 56), which has up to $56 \%$ of its molecular structure originating from plants. The epoxy resin was chosen due to its good adhesion with flax fibres. This resin and its hardener SD GP 505 were purchased from Sicomin Company. The mixing ratio between the resin and its hardener was 100:42 by weight. The mechanical and physical properties of green epoxy matrix were provided by the supplier $(\mathrm{E}=2.1 \mathrm{GPa}, \sigma=52 \mathrm{MPa}, \varepsilon=8.2 \%$, $\nu=0.4, \rho_{m}=1104.1 \mathrm{~kg} \mathrm{~m}^{-3}$ ).

The composite laminates were manufactured by compression moulding at ambient temperature. Firstly, the dry fabrics were manually pre-impregnated in a generous manner with the liquid resin using a hand roller. Secondly, each impregnated fabric was positioned and stacked according to the same orientation with resin layers. The whole assembly was placed between two steel trays covered with Teflon paper. Plates were then cured in a mold at ambient temperature for $24 \mathrm{~h}$. A pressure was applied by using the clamping bolts fixed at the ends of both steel trays. After the solidification of plates, they were polymerized in an oven at $40{ }^{\circ} \mathrm{C}$ for $24 \mathrm{~h}$, following one of the supplier's recommendations. To achieve the requested fibre volume fraction $V_{f}$, wedges were included between the two platens in order to control the constant thickness $h$ of plates, deducted from:

$h=\frac{n W}{V_{f} \rho_{f}}$

where $n$ is the number of plies.

Four fibre volume fractions were chosen: 25, 30, 35 and $40 \%$, which results in plates with thicknesses of $2.21,1.84,1.57$ and $1.36 \mathrm{~mm}$, respectively. For each fraction, plates of $300 \mathrm{~mm}$ by $300 \mathrm{~mm}$ were manufactured from 4 plies of UD flax fabric. Finally, the laminate plates were cut and shaped in rectangular forms by using a diamond saw blade. In addition to the four fibre volume fractions, the pure resin was also studied. In the next sections, studied composites will be designated by C25, C30, C35 and C40 for the chosen fibre volume fractions of $25,30,35$ and $40 \%$, respectively.

The final fibre volume fractions $V_{f}$ and the porosities $V_{p}$ of the studied laminates were experimentally determined by weighing the cured plates, the dry fabrics and by taking into account the density of flax fibres and the matrix, from the following equations:

$$
\begin{aligned}
& V_{f}=\frac{1}{1+\left(\frac{m_{c}-m_{f}}{m_{f}}\right)\left(\frac{\rho_{f}}{\rho_{m}}\right)} \\
& V_{p}=1-\frac{m_{c}}{L w h \cdot \rho_{m}}+\frac{n W}{h} \cdot\left(\frac{1}{\rho_{m}}-\frac{1}{\rho_{f}}\right)
\end{aligned}
$$

where $m_{c}$ and $m_{f}$ are the weights of the composite samples and the dry flax fabrics, respectively; $L, w$ and $h$ are the dimensions of the rectangular samples obtained from the cured plates (length, width and thickness).

The final fibre volume contents, porosity values and nominal thicknesses for different composites were given in Table 1 . Note that the final fibre volume contents were lower than those chosen due to the presence of porosities. 
Table 1

Fibre volume fraction, void volume fraction and nominal thickness of studied laminates.

\begin{tabular}{llll}
\hline $\begin{array}{l}\text { Composite } \\
\text { designation }\end{array}$ & $\begin{array}{l}\text { Fibre volume content } \\
V_{f_{i}}(\%)\end{array}$ & $\begin{array}{l}\text { Void volume content } \\
V_{p_{i}}(\%)\end{array}$ & $\begin{array}{l}\text { Nominal thickness } \\
(\mathrm{mm})\end{array}$ \\
\hline C25 & $23.08 \pm 0.18$ & $2.64 \pm 0.11$ & $2.21 \pm 0.01$ \\
C30 & $28.19 \pm 0.25$ & $2.47 \pm 0.05$ & $1.84 \pm 0.02$ \\
C35 & $33.61 \pm 0.32$ & $2.14 \pm 0.03$ & $1.57 \pm 0.01$ \\
C40 & $38.85 \pm 0.21$ & $1.95 \pm 0.11$ & $1.36 \pm 0.02$ \\
\hline
\end{tabular}

\subsection{Procedure of CLTE determination}

To evaluate the CLTE, the rectangular samples were polished in order to obtain clean edges, with smooth and parallel surfaces. For both longitudinal and transverse directions, $20 \mathrm{~mm}$ long samples on each side were used. To accurately measure the length of each specimen, a line parallel to the length was marked with an indelible ink marker on the surface of the specimen along its full length. According to the ASTM D6341 standard (ASTM D6341-16, 2016), all the samples were conditioned sequentially at three discrete temperatures and a relative humidity $(\mathrm{RH})$ controlled at $50 \pm 5 \%$ during $48 \mathrm{~h}$. The tested specimens were conditioned first in a freezer set $\left(T_{1}=-19.5 \pm 0.5{ }^{\circ} \mathrm{C}\right.$ at $\left.50 \% \mathrm{RH}\right)$, then at ambient temperature $\left(T_{0}=22.4 \pm 0.2{ }^{\circ} \mathrm{C}\right.$ at $\left.50 \% \mathrm{RH}\right)$, and finally in an environmental chamber $\left(T_{2}=59.9 \pm 0.1{ }^{\circ} \mathrm{C}\right.$ at $\left.50 \% \mathrm{RH}\right)$. After each condition, the specimen length was measured within $1 \mathrm{~min}$ of removal from the conditioning chamber. The measurements were made by a TMM (Global Statue 575 model of Hexagon Metrology) with a high precision of $\pm 10^{-5} \mathrm{~mm}$ according to the ASTM E831-06, 2006). Length measurements of the sample were carried out on the surfaces adjacent to the drawn lines at each end of the specimen. It is worth noting that, to minimize errors due to the formation of ice or condensation on the specimen surfaces, the surfaces were wiped with an absorbent cotton rag just prior to making the measurements.

The CLTE $\alpha$ for a specimen, whose initial length is $L_{0}$ at ambient temperature, is defined by the slope of the best-fit line of the curve of sample length variation $\left(\Delta L / L_{0}\right)$ versus temperature difference, given by:

$\frac{\Delta L}{L_{0}}=\alpha \Delta T$

where $\Delta L$ is the change in length of test specimen, in $\mathrm{mm}$, due to cooling or to heating; $L_{0}$ is the length of test specimen in $\mathrm{mm}$, at ambient temperature, and $\Delta T$ is the temperature difference, in Kelvin, for which the change in the length $\Delta L$ of the specimen is measured. Note that this testing method was used to determine the CLTE for both longitudinal and transverse directions, i.e. $\alpha_{L}$ and $\alpha_{T}$.

\section{Results and discussion}

\subsection{Experimental evaluation of the CLTE of UD composites}

Fig. 1 illustrates the relative longitudinal and transverse length variation $\left(\Delta L / L_{0}\right)$ according to the temperature difference $(\Delta T)$ of the C35 composite $\left(V_{f}=33.61 \%\right)$. Note that each point presents an average value and a standard deviation of 9 samples. To identify the CLTE of each specimen, the data were fitted by a straight linear regression and the slope of the curve, i.e. the CLTE, was calculated. One can notice that the relative length variation varies in a quasi-linear way with the increase of the temperature difference. All the correlation coefficients $\left(R^{2}\right)$ were larger than 0.99 . This indicates that the change of the thermal expansion strain with the applied temperature was linear.

The procedure described for the sample C35 was also applied to the other samples, i.e. the samples C25, C30, C40 and pure resin. The values of the CLTE of UD composites and pure resin were directly determined as the slope of the fitting curve as shown in Fig. 1 for the C35 composites. The maximum imprecision in the calculated coefficient of linear thermal expansion was calculated from the corresponding formula given by the ASTM E831-06 standard. This required in particular the imprecision in the measurement of $\Delta T$, which was measured and equal to $3 \pm 1 \mathrm{~K}$. This calculation was performed for each coefficient and the value of $7.6 \%$ was obtained on average for the maximum deviation.

For the pure resin, the CLTE in longitudinal and transverse directions are identical and equal to $38.5 \pm 2.93 \times 10^{-6} / \mathrm{K}$ and $38.1 \pm 2.89 \times 10^{-6} / \mathrm{K}$, respectively. This was expected due to the isotropy of green epoxy resin. Note that our value was close to the CLTE values given in the literature for other epoxy resins (Karadeniz and Kumlutas, 2007). Table 2 summarizes the obtained values of the longitudinal and transverse CLTE for all composites. One can notice that the CLTE values of the flax fibre composites in the transverse direction were more important in absolute value than those in the longitudinal one (from 36 to 55 times more important). This can be explained by the microstructure and anisotropic properties of wall components of the flax fibre (Baley et al., 2016). It can also be seen in Table 2 that the higher the fibre content, the lower the longitudinal CLTE value and the higher the transverse CLTE value.

\subsection{Estimation of the CLTE of flax fibre}

Measuring the CLTE of a flax fibre remains quite complicated. For this purpose, it was calculated from an inverse approach using the micromechanical models of Schapery (Schapery, 1968) and Chamis (Chamis, 1983) associated with an optimization program of Matlab software. (a)

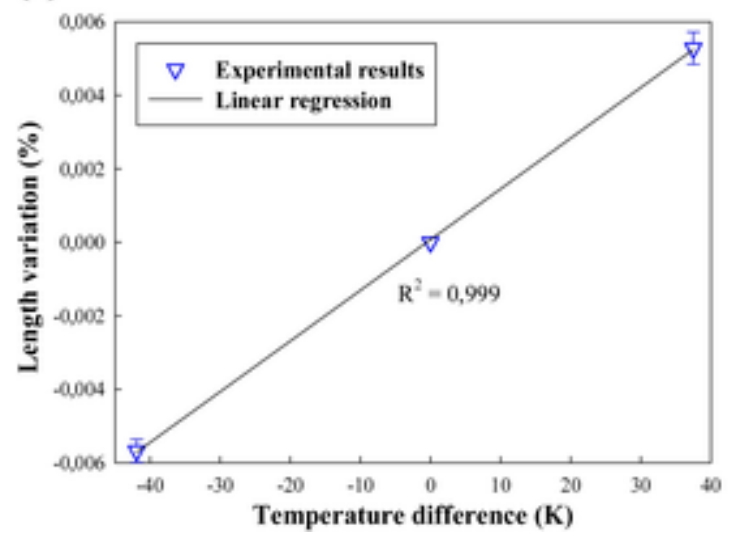

(b)

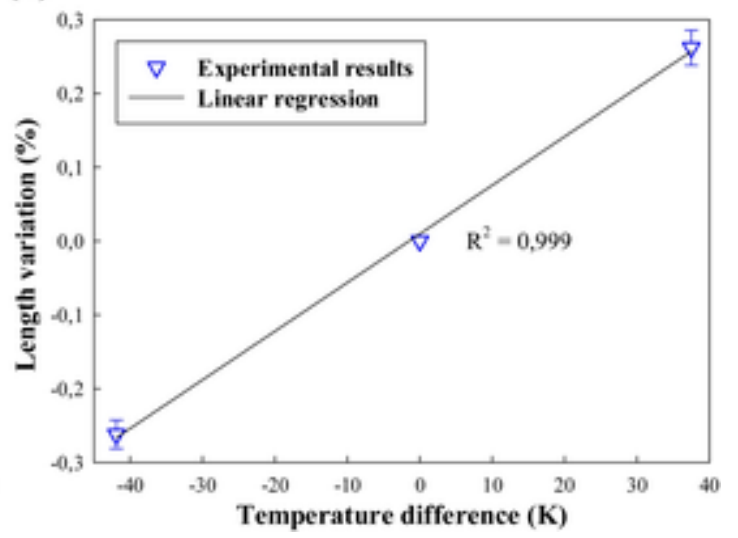

Fig. 1. Length variation of the $\mathrm{C} 35$ composite $\left(\mathrm{V}_{\mathrm{f}}=33.61 \%\right)$ as function of the temperature difference: a) longitudinal direction, b) transverse direction. 
Table 2

Coefficient of linear thermal expansion of studied laminates.

\begin{tabular}{|c|c|c|}
\hline \multirow[t]{2}{*}{ Composite designation } & \multicolumn{2}{|c|}{ Coefficient of thermal expansion $\alpha_{L / T}^{\operatorname{Exp}}\left(V_{f_{i}}\right)\left(\times 10^{-6} / \mathrm{K}\right)$} \\
\hline & Longitudinal direction $\left(\alpha_{\mathrm{L}}\right)$ & Transverse direction $\left(\alpha_{T}\right)$ \\
\hline $\mathrm{C} 25$ & $1.77 \pm 0.14$ & $63.24 \pm 4.81$ \\
\hline C30 & $1.57 \pm 0.12$ & $64.14 \pm 4.88$ \\
\hline C35 & $1.41 \pm 0.11$ & $65.11 \pm 4.95$ \\
\hline $\mathrm{C} 40$ & $1.23 \pm 0.09$ & $66.26 \pm 5.04$ \\
\hline
\end{tabular}

Based on energy principles, Schapery proposed an expression for the longitudinal CLTE of UD composites, i.e. $\alpha_{L}$, based on the longitudinal CLTE of the fibre. So, for the longitudinal CLTE, most micromechanical models derived identical expressions to Schapery's formulae, given by the following equation:

$\alpha_{L}\left(V_{f_{i}}\right)=\frac{E_{f_{L}} \alpha_{f_{L}} V_{f_{i}}+E_{m} \alpha_{m}\left(1-V_{f_{i}}-V_{p_{i}}\right)}{E_{f_{L}} V_{f_{i}}+E_{m}\left(1-V_{f_{i}}-V_{p_{i}}\right)}$

where $V_{f_{i}}$ and $V_{p_{i}}$ are the fibre volume fraction and the porosity volume fraction of the considered composite, respectively (Table 1). $E_{f_{L}}$ and $\alpha_{f_{L}}$ are the longitudinal modulus and CLTE of the fibre, respectively. $E_{m}$ and $\alpha_{m}$ are the experimental Young's modulus and the CLTE of the matrix, respectively.

For the transverse direction, several micromechanical models identified different expressions to estimate the transverse CLTE for UD composites. In this study, Chamis model, based on strength of materials approach, was used to evaluate the CLTE in the transverse direction (Eq. (6)). The choice of this model was mainly justified by the fact that it took into account the transversely isotropic behaviour of fibres. The expression of the transverse CLTE is given as follows:

$\alpha_{T}\left(V_{f_{i}}\right)=\alpha_{f_{T}} \sqrt{V_{f_{i}}}+\left(1-\sqrt{V_{f_{i}}}\right)\left(1+V_{f_{i}} \nu_{m} \frac{E_{f_{L}}}{E_{L}}\right) \alpha_{m}$

where $\alpha_{f_{T}}$ is the transverse CLTE of the fibre, $v_{m}$ is the Poisson's ratio of the matrix and $E_{L}$ is the elastic modulus for the longitudinal direction of different composites.

It is worth noting that in Eqs. (5) and (6), we considered a good adhesion between the flax fibre and the epoxy resin (Le Duigou et al., 2017). The porosities were also taken into account in the longitudinal CLTE evaluation (Eq. (5).

In this work, we used an average value of $51.7 \pm 9 \mathrm{GPa}$ for the modulus $E_{f_{L}}$ determined from tensile tests (not shown here) on flax fibres. This value is rather close to that obtained by Baley and Bourmaud (Baley and Bourmaud, 2014) for French elementary flax fibres $(52.5 \pm 8 \mathrm{GPa})$. For the matrix and different composites, the mechanical properties determined from the tensile tests according to the ASTM D3039 standard were used. Note that the tensile modulus was determined by calculating the slope of the initial linear portion of the stressstrain curve.

\subsubsection{Optimization program}

With the aim of estimating $\alpha_{f_{L}}$ or $\alpha_{f_{T}}$ of flax fibre from an inverse approach, the analytical solution (Eqs. (5) or (6)) by using the optimization toolbox of Matlab was applied to experimental data obtained from the different UD composites. This optimization was based on the minimization of the quadratic error $q$ as:

$q=\sum_{i=1}^{4}\left(\alpha_{L / T}\left(V_{f_{i}}\right)-\alpha_{L / T}^{E x p}\left(V_{f_{i}}\right)\right)^{2}$

where $\alpha_{L / T}\left(V_{f_{i}}\right)$ is the estimated CLTE for the UD composite with fibre content $V_{f_{i}}$ in the longitudinal or transverse direction assessed from Eq.
(5) or Eq. (6), respectively; $\alpha_{L / T}^{E x p}\left(V_{f_{i}}\right)$ is the average of CLTE in the longitudinal or transverse direction measured experimentally from the UD composite with fibre content $V_{f_{i}}$ (Table 2).

Initial values of $\alpha_{f_{L}}$ and $\alpha_{f_{T}}$ were then changed in order to minimize $q$, i.e. until the CLTE predicted by the analytical solution converged with those deducted from the experimental statements. This optimization procedure, giving optimum values of $\alpha_{f_{L}}$ and $\alpha_{f_{T}}$, was extensively described in our previous works (Saidane et al., 2016a, 2016b).

\subsubsection{Results}

Fig. 2 shows the evolution of the CLTE values of different composites as a function of fibre content in longitudinal and transverse directions. Fig. 2 indicates that the CLTE values of all composites predicted by Schapery and Chamis models were in agreement with the experimental ones in each direction, since $R^{2}$ was higher than 0.997 . As a reminder, knowing $\alpha_{L}$ and $\alpha_{T}$ of each UD composite and the matrix, the CLTE of the flax fibre in the longitudinal and transverse directions could be determined by the micromechanical models mentioned above. The execution of the optimization program associated with Eqs. (5) and (6) resulted in values of the $\alpha_{f_{L}}$ and $\alpha_{f_{T}}$ of the flax fibre equal to $1.2 \pm 0.1 \times 10^{-6} / \mathrm{K}$ and $75 \pm 5 \times 10^{-6} / \mathrm{K}$, respectively. These values were well correlated with the existing values in the literature ($1 \times 10^{-6} / \mathrm{K}$ for $\alpha_{f_{L}}$ (Pomel, 2003) and approximatively $78 \times 10^{-6} / \mathrm{K}$ for $\alpha_{f_{T}}$ (Gentles et al., 2010)). This highlights the accuracy of the method used in this work to evaluate the longitudinal and transverse CLTE of flax fibre. On the other hand, our values were well correlated with results obtained from a thermal mechanical technique for the single jute fibre at room temperature. Cichocki and Thomason (Cichocki and Thomason, 2002) found values of $\alpha_{f_{L}}$ and $\alpha_{f_{T}}$ equal to $-0.6 \times 10^{-6}$ and $77.2 \times 10^{-6} / \mathrm{K}$, respectively. This was mainly due to the fact that the structure of jute fibre is broadly similar to that of flax fibre (Gon et al., 2012). According to these results, it should be noted that natural fibres exhibit a negative CLTE in the longitudinal direction. This behaviour was also observed in the case of traditional fibres such as Kevlar fibres (Rojstaczer et al., 1985). In contrast, the CLTE in the transverse direction was positive and exceeding $70 \times 10^{-6} / \mathrm{K}$. Finally, it was shown that the $\alpha_{f_{T}}$ of the flax fibre was approximatively 63 times more important than that of $\alpha_{f_{L}}$. This difference was due to the hierarchical microstructure and anisotropic properties of wall components of flax fibres.

The results also show that the experimental CLTE of UD composites in the transverse direction was higher than that in the longitudinal direction and that of green epoxy resin. In fact, the fibre stiffness mostly prevents the matrix expansion in the longitudinal direction. This forces

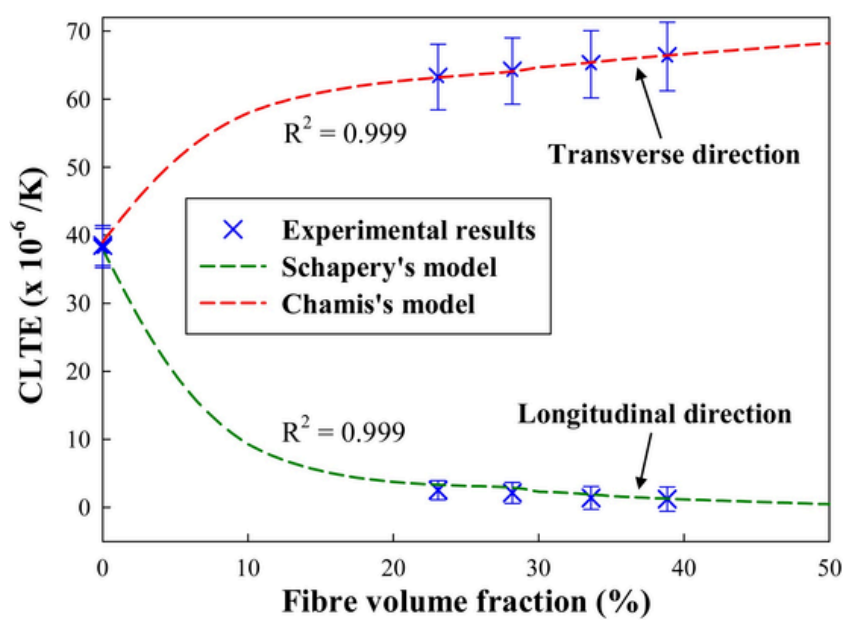

Fig. 2. Experimental coefficients of linear thermal expansion of different composites as function of fibre volume fraction. 
the matrix to expand considerably in the transverse direction (Tezvergil et al., 2003).

\subsection{Application to the calculation of internal stresses}

In this Section, the internal stresses induced by the thermal expansion were estimated in symmetric and antisymmetric cross-ply laminates $\left([0 / 90]_{s}\right.$ and $[0 / 90 / 0 / 90]$, respectively). An example of the stacking sequence of the symmetric cross-ply laminate is shown in Fig. 3. The aim of this calculation, performed on a concrete example, was to estimate the influence of temperature variation itself on the internal stresses. The laminate was made of four UD layers of $1 \mathrm{~mm}$ thick with the following mechanical characteristics determined from the same procedure described in (Scida et al., 2017) for $V_{f}=40 \%$ : $\mathrm{E}_{\mathrm{L}}=22.3 \mathrm{GPa}, \mathrm{E}_{\mathrm{T}}=3.7 \mathrm{GPa}, \nu_{\mathrm{LT}}=0.44$ and $\mathrm{G}_{\mathrm{LT}}=1.15 \mathrm{GPa}$. The corresponding values of the $\alpha_{L}$ and $\alpha_{T}$ of the laminate was equal to $1.08 \pm 0.08 \times 10^{-6} / \mathrm{K}$ and $67.2 \pm 5.1 \times 10^{-6} / \mathrm{K}$. The estimation of internal stresses was made by a $2 \mathrm{D}$ analytical model based on classical laminate theory. The thermo-mechanical behaviour of the composite was governed by a linear elastic constitutive law taking into account the expansion strains induced by thermal effects. Finally, the effect of the temperature difference $(\Delta T)$ and the stacking sequence on the internal stresses was studied.

\subsubsection{Classical laminate theory (CLT)}

In practice, the composite structures are submitted to temperature variations during their manufacturing process as well as during their service. The first effect of the temperature variation is the reduction of the mechanical properties and the durability of the final structure. In addition, the temperature variation generates a thermal expansion of the material. The thermal expansion phenomena can be described by writing the thermal strains of the laminate $\left(\varepsilon_{i}^{*}\right)$ at point $(x, y, z)$ and at instant $t$ as:

$\varepsilon_{i}^{*}=\alpha_{i} \Delta T(x, y, z, t)$

where $\alpha_{i}$ are the thermal expansion coefficients, $\Delta T$ is the temperature variation.

Other phenomena can induce some effects analogous to thermal effects, such as absorption of humidity or gas. Note that the corresponding strains (as swelling strains) were not considered since this study was only focused on thermal effects.

The law of elasticity was first defined in a reference state where the strains due to thermal expansion were zero. In order to take into account only the thermal expansion phenomena, the law of elasticity was modified and given by the following relation:

$\varepsilon_{i}=\sum_{j=1}^{6} S_{i j} \sigma_{j}+\varepsilon_{i}^{*}$

where $S_{i j}$ are the compliance matrix components.
The inverse form of the law of elasticity (Eq. 9) is written as:

$\sigma_{i}=\sum_{j=1}^{6} C_{i j}\left(\varepsilon_{j}-\varepsilon_{j}^{*}\right)$

where $C_{i j}$ are the stiffness matrix components.

Thus, in the case of orthotropic materials, the law of elasticity in Eq. 10 , reported to main axes, is written as:

$\left\{\begin{array}{l}\sigma_{1} \\ \sigma_{2} \\ \sigma_{3} \\ \sigma_{4} \\ \sigma_{5} \\ \sigma_{6}\end{array}\right\}$

$=\left[\begin{array}{cccccc}C_{11} & C_{12} & C_{13} & 0 & 0 & 0 \\ C_{12} & C_{22} & C_{23} & 0 & 0 & 0 \\ C_{13} & C_{23} & C_{33} & 0 & 0 & 0 \\ 0 & 0 & 0 & D_{44} & 0 & 0 \\ 0 & 0 & 0 & 0 & D_{55} & 0 \\ 0 & 0 & 0 & 0 & 0 & D_{66}\end{array}\right]\left\{\begin{array}{l}\varepsilon_{1}-\varepsilon_{1}^{*} \\ \varepsilon_{2}-\varepsilon_{2}^{*} \\ \varepsilon_{3}-\varepsilon_{3}^{*} \\ \varepsilon_{4}-\varepsilon_{4}^{*} \\ \varepsilon_{5}-\varepsilon_{5}^{*} \\ \varepsilon_{6}-\varepsilon_{6}^{*}\end{array}\right\}$

For a plane-stress state by introducing the components $Q_{i j}$ of the reduced stiffness matrix, the Eq. (11) is reduced as:

$$
\left\{\begin{array}{l}
\sigma_{1} \\
\sigma_{2} \\
\sigma_{6}
\end{array}\right\}=\left[\begin{array}{ccc}
Q_{11} & Q_{12} & 0 \\
Q_{12} & Q_{22} & 0 \\
0 & 0 & Q_{66}
\end{array}\right]\left\{\begin{array}{c}
\varepsilon_{1}-\varepsilon_{1}^{*} \\
\varepsilon_{2}-\varepsilon_{2}^{*} \\
\varepsilon_{6}-\varepsilon_{6}^{*}
\end{array}\right\}
$$

Reduced stiffness matrix $\left[Q_{i j}\right]$ of a UD laminate layer is calculated using the elastic engineering constants of the material, as:

$[Q]=\left[\begin{array}{ccc}\frac{E_{L}}{1-v_{T L} v_{L T}} & \frac{v_{T L} E_{L}}{1-v_{T L} v_{L T}} & 0 \\ \frac{v_{T L} E_{L}}{1-v_{T L} v_{L T}} & \frac{E_{T}}{1-v_{T L} v_{L T}} & 0 \\ 0 & 0 & G_{L T}\end{array}\right]$

For a layer $k$ oriented by an angle $\theta$ with respect to the reference axes $(x, y, z)$, the law of elasticity given by Eq.(12) becomes when reported to these axes:

$\left\{\begin{array}{l}\sigma_{x x} \\ \sigma_{y y} \\ \sigma_{x y}\end{array}\right\}_{k}=\left[\begin{array}{lll}\bar{Q}_{11} & \bar{Q}_{12} & \bar{Q}_{16} \\ \bar{Q}_{12} & \bar{Q}_{22} & \bar{Q}_{26} \\ \bar{Q}_{16} & \bar{Q}_{26} & \bar{Q}_{66}\end{array}\right]_{k}\left\{\begin{array}{l}\varepsilon_{x x}-\varepsilon_{x x}^{*} \\ \varepsilon_{y y}-\varepsilon_{y y}^{*} \\ \gamma_{x y}-\gamma_{x y}^{*}\end{array}\right\}$

where $\bar{Q}_{i j}$ are the components of the transformed reduced stiffness matrix of the material expressed in the global coordinates of the laminate which are obtained from the Eq. (15). $\varepsilon_{i j}^{*}$ are the in-plane components of the thermal strain vectors.

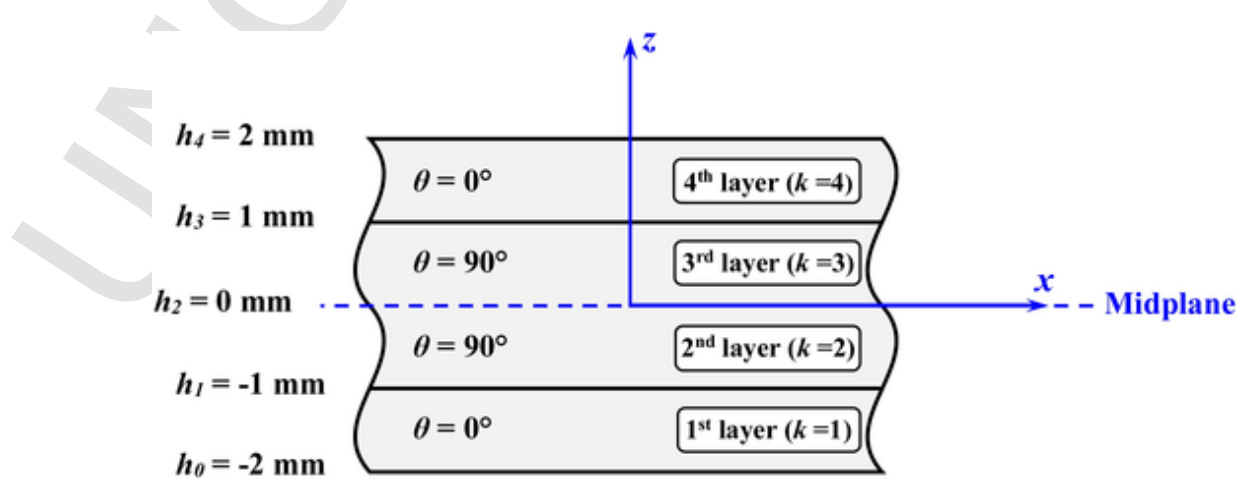

Fig. 3. Symmetric cross-ply laminate $\left([0 / 90]_{s}\right)$. 


$$
\begin{aligned}
& \bar{Q}_{11}=Q_{11} c^{4}+Q_{22} s^{4}+2\left(Q_{12}+2 Q_{66}\right) s^{2} c^{2} \\
& \bar{Q}_{12}=\left(Q_{11}+Q_{22}-4 Q_{66}\right) s^{2} c^{2}+Q_{12}\left(s^{4}+c^{4}\right) \\
& \bar{Q}_{22}=Q_{11} s^{4}+Q_{22} c^{4}+2\left(Q_{12}+2 Q_{66}\right) s^{2} c^{2} \\
& \bar{Q}_{16}=\left(Q_{11}-Q_{12}-2 Q_{66}\right) s c^{3}+\left(Q_{12}-Q_{22}+2 Q_{66}\right) s^{3} c \\
& \bar{Q}_{26}=\left(Q_{11}-Q_{12}-2 Q_{66}\right) s^{3} c+\left(Q_{12}-Q_{22}+2 Q_{66}\right) s c^{3} \\
& \bar{Q}_{66}=\left[Q_{11}+Q_{22}-2\left(Q_{12}+Q_{66}\right)\right] s^{2} c^{2}+Q_{66}\left(s^{4}+c^{4}\right)
\end{aligned}
$$

where $c=\cos \theta, s=\sin \theta$ and $\theta$ is the orientation angle of the considered layer.

The strains $\left(\varepsilon_{x x}, \varepsilon_{y y}, \gamma_{x y}\right)$ in Eq. (14) are expressed as follow:

$$
\left\{\begin{array}{c}
\varepsilon_{x x} \\
\varepsilon_{y y} \\
\gamma_{x y}
\end{array}\right\}=\left\{\begin{array}{c}
\varepsilon_{x x}^{0} \\
\varepsilon_{y y}^{0} \\
\gamma_{x y}^{0}
\end{array}\right\}+z\left\{\begin{array}{l}
\kappa_{x x} \\
\kappa_{y y} \\
\kappa_{x y}
\end{array}\right\}
$$

where $\varepsilon_{x x}^{0}, \varepsilon_{y y}^{0}, \gamma_{x y}^{0}$ are the midplane strains and $\kappa_{x x}, \kappa_{y y}, \kappa_{x y}$ are the curvatures.

The thermal strains $\left(\varepsilon_{x x}^{*}, \varepsilon_{y y}^{*}, \gamma_{x y}^{*}\right)$ are expressed in the global coordinate system only as functions of thermal strains $\varepsilon_{11}^{*}$ and $\varepsilon_{22}^{*}$, which are referred to the layer directions. Indeed, the thermal expansion phenomena have in practice no effect on the shear strains. They are defined by the following equation:

$\left\{\begin{array}{l}\varepsilon_{x x}^{*} \\ \varepsilon_{y y}^{*} \\ \gamma_{x y}^{*}\end{array}\right\}_{k}=\left[\begin{array}{cc}\mathrm{c}^{2} & s^{2} \\ s^{2} & \mathrm{c}^{2} \\ 2 \mathrm{sc} & -2 \mathrm{sc}\end{array}\right]\left\{\begin{array}{l}\varepsilon_{11}^{*} \\ \varepsilon_{22}^{*}\end{array}\right\}$

where:

$\varepsilon_{11}^{*}=\alpha_{L} \Delta T(x, y, z, t)$

$\varepsilon_{22}^{*}=\alpha_{T} \Delta T(x, y, z, t)$

The CLT approach requires characterising the relation of laminate forces and moments to strains and curvatures. This means introducing the mechanical loading, which is composed of forces per unit length $N x$, $N y, N x y$ and moments per unit length $M x, M y, M x y$. Note that those resultant forces and moments acting on the laminate are related to the stresses in each layer by integration through the laminate thickness. Thus, relations incorporating forces and moments can replace the stress-strain relations leading to the constitutive equation of the CLT. When thermal expansion is taken into account, the constitutive equation based on midplane strains and curvatures differs since the resultants and moments owed to the thermal expansion processes are included as follow:

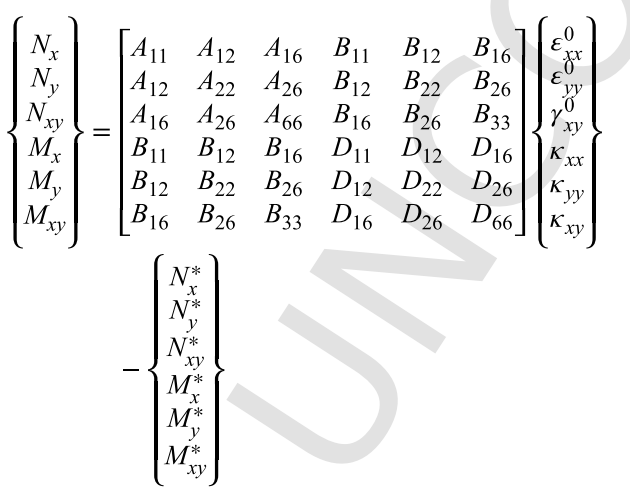

where $A_{i j}, B_{i j}, D_{i j}$ are the coefficients of the matrices [A], [B], and [D] referred to as extension, bending-extension coupling and bending stiffness respectively, given by Eq. (20). The in-plane resultants $N_{x}{ }^{*}, N_{y}{ }^{*}$, $N_{x y}{ }^{*}$ and the resultant moments $M_{x}{ }^{*}, M_{y}{ }^{*}, M_{x y}{ }^{*}$ due to the dilatation phenomena are given by Eq. (21).

$$
\begin{aligned}
A_{i j} & =\sum_{k=1}^{n}\left(h_{k}-h_{k-1}\right)\left(\overline{Q_{i j}}\right)_{k} \\
B_{i j} & =\frac{1}{2} \sum_{k=1}^{n}\left(h_{k}^{2}-h_{k-1}^{2}\right)\left(\overline{Q_{i j}}\right)_{k} \\
D_{i j} & =\frac{1}{3} \sum_{k=1}^{n}\left(h_{k}^{3}-h_{k-1}^{3}\right)\left(\overline{Q_{i j}}\right)_{k}
\end{aligned}
$$

where $n$ represents the number of layers and $h_{k}$ is the distance from the mid-plane to top $k_{t h}$ layer.

$$
\begin{aligned}
& \left(N_{x}^{*}, M_{x}^{*}\right)=\sum_{k=1}^{n} \int_{h_{k-1}}^{h_{k}}\left(\overline{Q_{11}} \varepsilon_{x x}^{*}+\overline{Q_{12}} \varepsilon_{y y}^{*}+\overline{Q_{16}} \gamma_{x y}^{*}\right)_{k}(1, \quad z) d z \\
& \left(N_{y}^{*}, M_{y}^{*}\right)=\sum_{k=1}^{n} \int_{h_{k-1}}^{h_{k}}\left(\overline{Q_{12}} \varepsilon_{x x}^{*}+\overline{Q_{22}} \varepsilon_{y y}^{*}+\overline{Q_{26}} \gamma_{x y}^{*}\right)_{k}(1, \quad z) d z(21 . \\
& \left(N_{x y}^{*}, M_{x y}^{*}\right)=\sum_{k=1}^{n} \int_{h_{k-1}}^{h_{k}}\left(\overline{Q_{16}} \varepsilon_{x x}^{*}+\overline{Q_{26}} \varepsilon_{y y}^{*}+\overline{Q_{66}} \gamma_{x y}^{*}\right)_{k}(1, \quad z) d z
\end{aligned}
$$

The midplane strains $\varepsilon_{x x}^{0}, \varepsilon_{y y}^{0}, \gamma_{x y}^{0}$ and curvatures $\kappa_{x x}, \kappa_{y y}, \kappa_{x y}$ are determined according to the resultants and moments of the constitutive equation (Eq.(19)) without external mechanical load ( $N=M=0$ ) on the laminate as following:

$\left\{\begin{array}{l}\varepsilon_{x x}^{0} \\ \varepsilon_{y y}^{0} \\ \gamma_{x y}^{0} \\ \kappa_{x x} \\ \kappa_{y y} \\ \kappa_{x y}\end{array}\right\}$

$=\left[\begin{array}{llllll}A_{11} & A_{12} & A_{16} & B_{11} & B_{12} & B_{16} \\ A_{12} & A_{22} & A_{26} & B_{12} & B_{22} & B_{26} \\ A_{16} & A_{26} & A_{66} & B_{16} & B_{26} & B_{33} \\ B_{11} & B_{12} & B_{16} & D_{11} & D_{12} & D_{16} \\ B_{12} & B_{22} & B_{26} & D_{12} & D_{22} & D_{26} \\ B_{16} & B_{26} & B_{33} & D_{16} & D_{26} & D_{66}\end{array}\right]^{-1}\left\{\begin{array}{l}N_{x}^{*} \\ N_{y}^{*} \\ N_{x y}^{*} \\ M_{x}^{*} \\ M_{y}^{*} \\ M_{x y}^{*}\end{array}\right\}$

Finally, the internal stresses in the layer $k$ are expressed by the relation:

$\left\{\begin{array}{l}\sigma_{x x} \\ \sigma_{y y} \\ \sigma_{x y}\end{array}\right\}_{k}=\left[\begin{array}{lll}\bar{Q}_{11} & \bar{Q}_{12} & \bar{Q}_{16} \\ \bar{Q}_{12} & \bar{Q}_{22} & \bar{Q}_{26} \\ \bar{Q}_{16} & \bar{Q}_{26} & \bar{Q}_{66}\end{array}\right]_{k}\left\{\begin{array}{l}\varepsilon_{x x}^{0}+z \kappa_{x x}-\varepsilon_{x x}^{*} \\ \varepsilon_{y y}^{0}+z \kappa_{y y}-\varepsilon_{y y}^{*} \\ \gamma_{x y}^{0}+z \kappa_{x y}-\gamma_{x y}^{*}\end{array}\right\}$

\subsubsection{Internal stresses of the cross-ply laminates}

The distribution of internal stresses through the laminate thickness is obtained using the Eq. (23). Fig. 4 represents the internal stresses $\sigma_{x x}$, $\sigma_{y y}$ and $\sigma_{x y}$ distribution through the thickness of the symmetric and antisymmetric cross-ply laminates for a temperature variation $\Delta T=$ $-50 \mathrm{~K}$. For the symmetric laminate (Fig. 4a), one can note that the internal stresses are constant and uniform in each layer due to the symmetry of the laminate. The results show that externals $0^{\circ}$ plies are subject only to a compressive stress of $-9.3 \pm-0.7 \mathrm{MPa}$ in the x-direction and to a tensile stress of $9.3 \pm 0.7 \mathrm{MPa}$ in the y-direction. Due to the stacking sequence (i.e. symmetric cross-ply laminate), the opposite was expected and finally observed for the internal $90^{\circ}$ plies ( $\sigma_{x x}=$ $9.3 \pm 0.7 \mathrm{MPa}$ and $\sigma_{y y}=-9.3 \pm-0.7 \mathrm{MPa}$ ). Note that the calculated shear stress $\sigma_{x y}$ is equal to zero whatever the layer orientation. It can be concluded that the internal stresses in each direction remain invariable with the thickness in the layers with the same orientation. The absolute values of $\sigma_{x x}$ and $\sigma_{y y}$ are identical for the $0^{\circ}$ and $90^{\circ}$ plies.

In contrast to that was observed for the symmetric laminate, the internal stresses are not uniform in the thickness of each laminate layer (Fig. 4b). The corresponding values change layer by layer for both cases. The results show that $0^{\circ}$ plies undergo only a compressive stress in the $\mathrm{x}$-direction with variations ranging from $-2.4 \pm-0.3$ to $-7.1 \pm-$ $0.6 \mathrm{MPa}$ for the first layer and from $-11.9 \pm-0.9$ to $-16.6 \pm-1.3 \mathrm{MPa}$ for the third layer. In the y-direction, the $0^{\circ}$ plies are submitted to ten- 
(a)

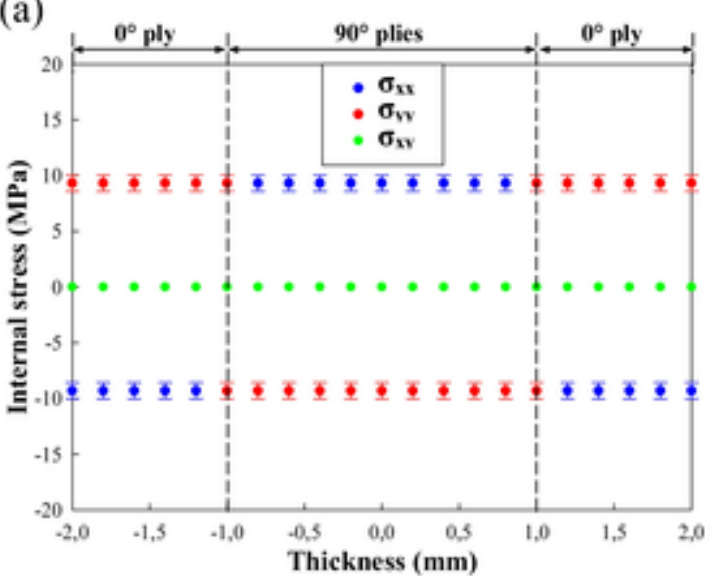

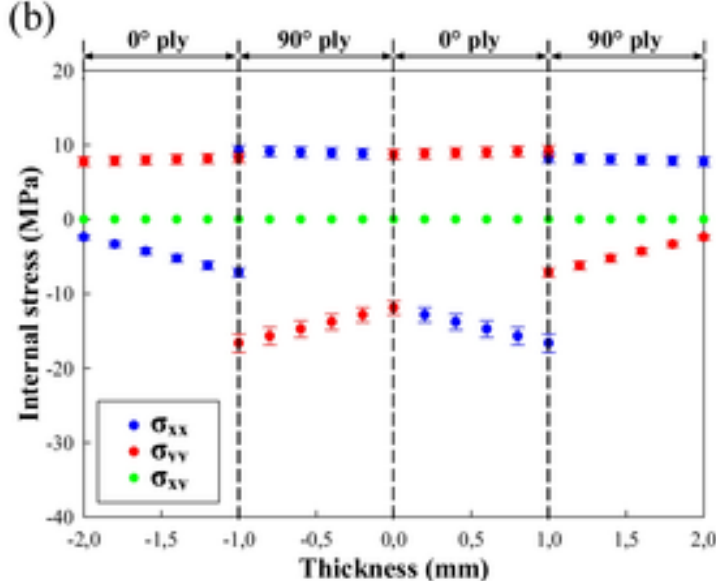

Fig. 4. Internal stresses distribution through the thickness of the cross-ply laminate for $\Delta T=-50 \mathrm{~K}$ : a) symmetric laminate, b) antisymmetric laminate.

sile stresses, between $7.8 \pm 0.6$ and $8.3 \pm 0.7 \mathrm{MPa}$ for the first layer and between $8.7 \pm 0.7$ and $9.2 \pm 0.7 \mathrm{MPa}$ for the third layer. Inversely, the $90^{\circ}$ plies are subjected to tensile stresses in the x-direction (2nd layer: $9.2 \pm 0.7-8.7 \pm 0.7 \mathrm{MPa}$ and 4th layer: $8.3 \pm 0.7-7.8 \pm 0.6 \mathrm{MPa}$ ). In the y-direction, the compressive stresses vary between $-16.6 \pm-0.7 \mathrm{MPa}$ and-11.9 $\pm-0.7 \mathrm{MPa}$ for the second layer and between $-7.1 \pm-0.7$ and $-2.4 \pm 0.6 \mathrm{MPa}$ the fourth layer. These variations are mainly due to the presence of the curvatures in the antisymmetric laminate. As observed for the symmetric laminate, the calculated shear stress $\sigma_{x y}$ for the antisymmetric laminate is also equal to zero.

By comparing the symmetrical and antisymmetrical stacking, the values of $\sigma_{x x}$ and $\sigma_{y y}$ vary from -9.3 $\pm-0.7-9.3 \pm 0.7 \mathrm{MPa}$ for the symmetric laminate and from -16.6 $\pm-0.7-9.2 \pm 0.7 \mathrm{MPa}$ for the antisymmetric laminate. Consequently, to minimise the damages induced by the internal stresses, it is more interesting to choose the symmetric $[0 / 90]_{s}$ laminate because the compressive stresses are lower and constant in each layer. Indeed, some compressive stresses of the antisymmetric laminate are higher with large variations in each layer, which can lead to degradation mechanisms of natural fibre composites and amplification of internal damage.

\subsubsection{Effect of temperature difference and layer orientation on the internal} stresses

This sub-section deals first with the effect of temperature on the internal stresses of laminates characterised by a layer orientation varying from 0 to $90^{\circ}$. Fig. 5 shows the results of the symmetric laminate $[0 / \theta]_{\mathrm{s}}$ for different $\Delta T$. The values of $\Delta T$ were chosen according to the three different curing cycles recommended by the green epoxy resin supplier: $24 \mathrm{~h}$ at $313 \mathrm{~K}, 16 \mathrm{~h}$ at $333 \mathrm{~K}$ or $8 \mathrm{~h}$ at $353 \mathrm{~K}$. The corresponding value of $\Delta T$ are $-20,-40$ and $-60 \mathrm{~K}$ with respect to an operating temperature of $293 \mathrm{~K}$. Because of the symmetry of the laminate, internal stress values are presented only for the externals $0^{\circ}$ plies of the laminate in Fig. 5. The symmetric stacking sequence considered is $[0 / \theta]_{s}$. The value of $\theta$ was incremented in steps of $10^{\circ}$ from $10^{\circ}$ to $90^{\circ}$. As expected, results show that the temperature has a significant influence on the internal stresses of the composite laminates. In fact, the internal stresses increase in absolute values when increasing the temperature difference. For $\Delta T=-20 \mathrm{~K}$, the internal stresses $\sigma_{x x}, \sigma_{y y}$ and $\sigma_{x y}$ are equal to -3.7, 3.7 and $0 \mathrm{MPa}$, respectively, for $\theta=90^{\circ}$. When the temperature difference is two or three times higher $(\Delta T=-40$ or $-60 \mathrm{~K})$, these stresses become two or three times higher than those at $-20 \mathrm{~K}$, which is an expected result. The results also reveal that the angle $\theta$ has a significant influence on the internal stresses of composite laminates. The normal stresses $\sigma_{x x}$ and $\sigma_{y y}$ increase in absolute value with the angle $\theta$, while the stress $\sigma_{x y}$ increases between 0 and $60^{\circ}$ and decrease from $60^{\circ}$. At $\theta=45^{\circ}$, all three stresses are identical in absolute value. Whatever the temperature variation, the normal stresses $\sigma_{x x}$ and $\sigma_{y y}$ reach their maximum absolute values at $\theta=90^{\circ}$ and are equal to zero for the $0^{\circ}$ angle. Another trend is observed for the in-shear stresses $\sigma_{x y}$, with maximum values occurring at $\theta=60^{\circ}$ and zero values at $\theta=0$ and $90^{\circ}$. The knowledge of the plane stresses enabled us to estimate the principal internal stresses $\sigma_{1}$ and $\sigma_{2}$ and to find that they increase linearly with the orientation angle $\theta$. The same conclusion was reported in the case of carbon fibre-reinforced epoxy composites (Gong et al., 2015).

To conclude on the choice of the green resin curing cycle, a temperature of $313 \mathrm{~K}$ is recommended during the manufacturing of symmetric laminate if the cycle duration is not a constraining factor. Thus, the internal stress amplitude in the worst case remains moderate between $3.7 \pm-0.3$ and $3.7 \pm 0.3 \mathrm{MPa}$ at $313 \mathrm{~K}$, which is three times lower than at $353 \mathrm{~K}$.

The second step investigated the effect of the stacking sequence on the internal stresses for $\Delta T=-50 \mathrm{~K}$. For this purpose, other configurations were considered by varying the orientation angle $\theta$ in the antisymmetric laminate described by the $[0 / \theta / 0 / \theta]$ stacking $\left(\theta=30^{\circ}, 45^{\circ}\right.$ and $60^{\circ}$ ). The obtained results are shown in Fig. 6 indicating that the internal stresses distribution through the thickness laminate exhibits a similar tendency for all stacking sequences. Although the internal stresses distribution is identical, their values vary according to the orientation angle $\theta$. The [0/90/0/90] laminate presents the highest values of normal stresses $\sigma_{x x}$ and $\sigma_{y y}$ in both compression and tension for the most of layers. For the in-shear stresses $\sigma_{x y}$, the highest negative and positive values are found in the $[0 / 60 / 0 / 60]$ laminate. This result agrees with the previous finding for the symmetrical laminate, which reaches its maximum stress at $60^{\circ}$. Fig. 6 also shows that, among the studied stacking sequences, the $[0 / 30 / 0 / 30]$ stacking presents the best compromise on the internal stresses $\sigma_{x x}, \sigma_{y y}$ and $\sigma_{x y}$ since they are the lowest. The results highlight the importance of choosing an optimised stacking sequence, such as the $[0 / 30 / 0 / 30]$, prior to the manufacturing process, in order to obtain flax fibre composites with low internal stresses.

\section{Conclusions}

In this study, the longitudinal and transverse CLTE of flax fibres were experimentally evaluated from an inverse approach using two micromechanical models. This approach required first measuring the CLTE of UD composites with various fibre contents. The use of Schapery and Chamis models enabled us to evaluate the CLTE of flax fibres in longitudinal and transverse directions. The results of the inverse approach showed that flax fibres exhibit a negative CLTE in the longitudinal direction, which was equal to $-1.2 \pm 0.1 \times 10^{-6} / \mathrm{K}$. In contrast, the CLTE in the transverse direction was positive and equal to $75 \pm 5 \times 10^{-6} / \mathrm{K}$, highlighting the highly anisotropic properties of flax fibres. The knowledge of these two CLTE made it possible to predict 
(a)

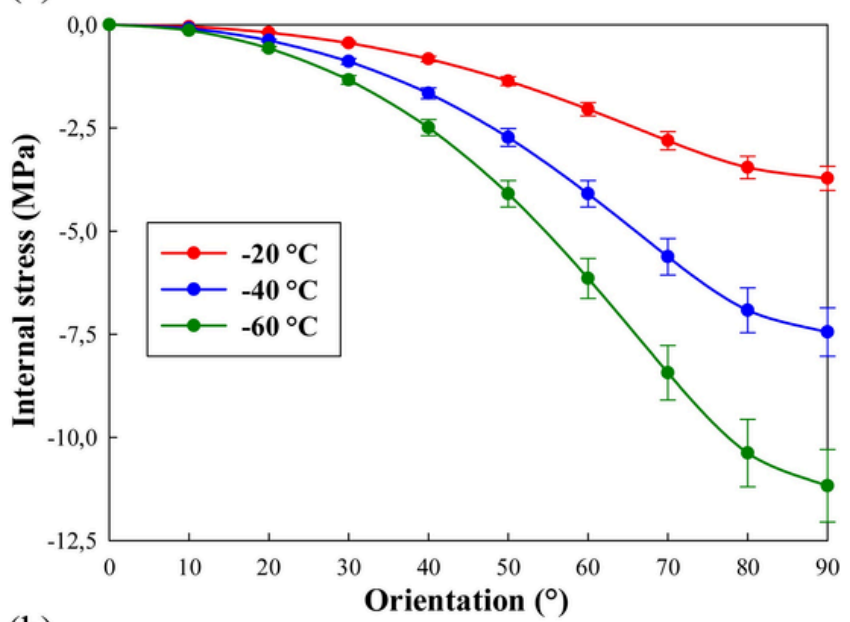

(b)

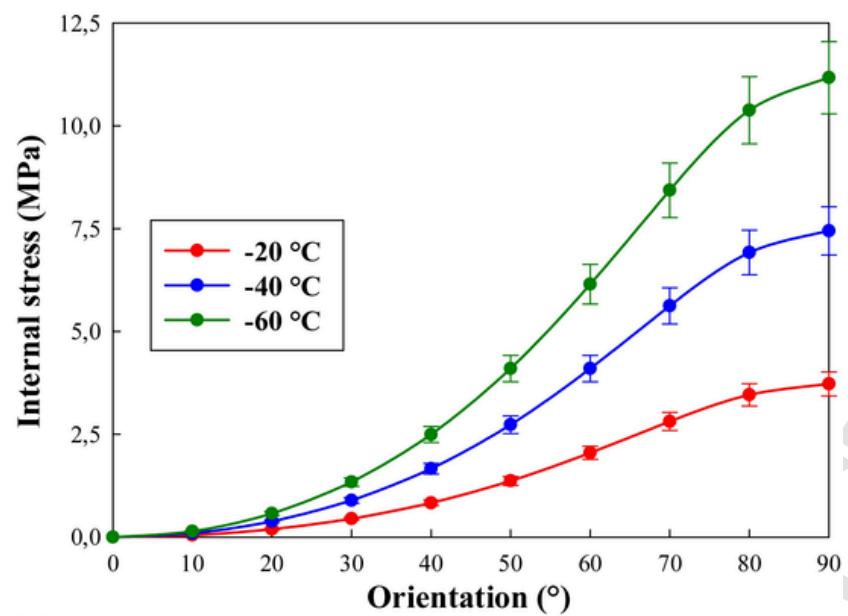

(c)

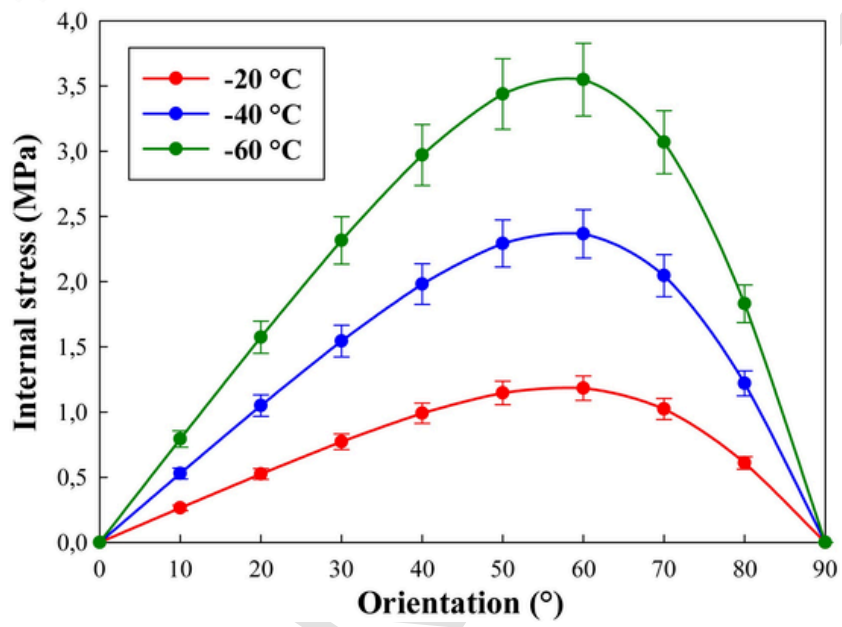

Fig. 5. Internal stresses of $0^{\circ}$ plies vs. ply orientation for $\Delta T=-20,-40,-60 \mathrm{~K}$ in symmetric laminate $[0 / \theta]_{s}$ : a) $\sigma_{x x}$, b) $\sigma_{y y}$, c) $\sigma_{x y}$.

the internal stresses of various laminates, such as cross-ply, $[0 / \theta]_{s}$ and $[0 / \theta / 0 / \theta]$. This prediction was made by a $2 \mathrm{D}$ analytical model based on classical laminate theory, taking into account the expansion strains induced by thermal effects. The main findings of the analysis of the internal stress in flax-fibre laminates can be summarised as follows:
- Choosing a symmetric cross-ply laminate was more interesting for minimising the internal stresses because the compressive stresses were lower and constant in each layer. Indeed, some compressive stresses of the antisymmetric laminate were higher with large variations in each layer, which could lead to degradation mechanisms of flax fibre laminates and amplification of its internal damage.

- Whatever the temperature variation, the normal stresses $\sigma_{x x}$ and $\sigma_{y y}$ of symmetric laminates reached their maximum absolute values for the $[0 / 90]_{s}$ stacking and were equal to zero for the $[0 / 0]_{s}$ stacking. Another trend was observed for the in-shear stress $\sigma_{x y}$, with maximum values occurring in the $[0 / 60]_{s}$ stacking and zero values in the $[0 / 0]_{s}$ and $[0 / 90]_{s}$ stacking sequences.

- With regard to the choice of curing cycle for the green resin, a temperature of $313 \mathrm{~K}$ was recommended when manufacturing symmetrical laminate if the cycle duration was not a constraining factor. Thus, the internal stress amplitude in the worst case remained moderate $( \pm 3.7 \mathrm{MPa})$ at $313 \mathrm{~K}$, three times lower than at $353 \mathrm{~K}$.

- For antisymmetric laminates, the highest stress values were found for the [0/90/0/90] stacking regarding the normal stresses in both compression and tension, and for the [0/60/0/60] stacking regarding the shear stresses. Among the studied stacking sequences, the $[0 / 30 / 0 / 30]$ stacking presented the best compromise on the internal internal stresses $\sigma_{x x}, \sigma_{y y}$ and $\sigma_{x y}$ since they were the lowest.

The results obtained in this study made it possible to quantify the effect of a temperature variation on the internal stresses. This effect should be taken into consideration as it could induce degradation within the flax fibre laminate and be a source of its internal damage. This study highlighted the importance of choosing an optimised stacking sequence prior to the manufacturing process, in order to obtain flax fibre composites with low internal stresses. It provided reliable data to help designers in dimensioning calculation and thus in future decision making.

\section{Funding}

This research did not receive any specific grant from funding agencies in the public, commercial, or not-for-profit sectors.

\section{Author contributions}

El Hadi Saidane: Conceptualization, Methodology, Formal analysis, Investigation, Methodology, Writing - review \& editing. Daniel Scida: Conceptualization, Methodology, Formal analysis, Investigation, Methodology, Writing - review \& editing. Rezak Ayad: Supervision, Conceptualization, Writing - review \& editing.

\section{Declaration of Competing Interest}

The authors declare that they have no known competing financial interests or personal relationships that could have appeared to influence the work reported in this paper.

\section{Acknowledgements}

The authors would like to gratefully acknowledge Olivier Cabot for his technical support and contribution to the taking of measurements on the 3D measuring machine. 
(a)

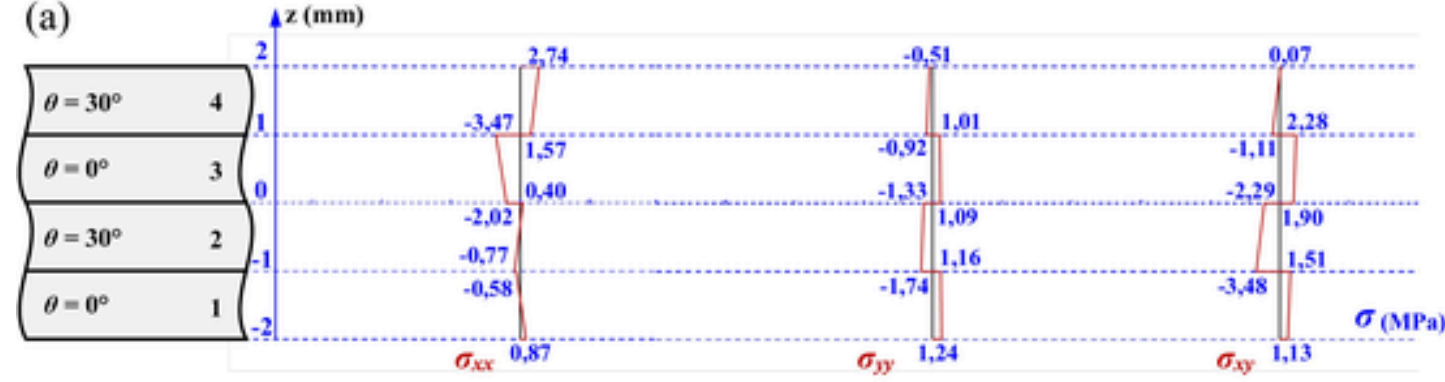

(b)

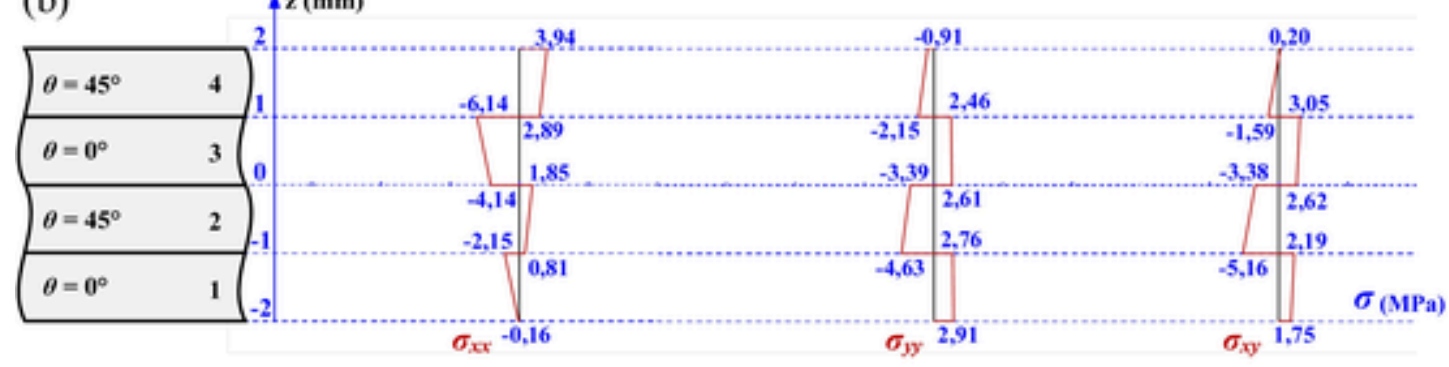

(c)

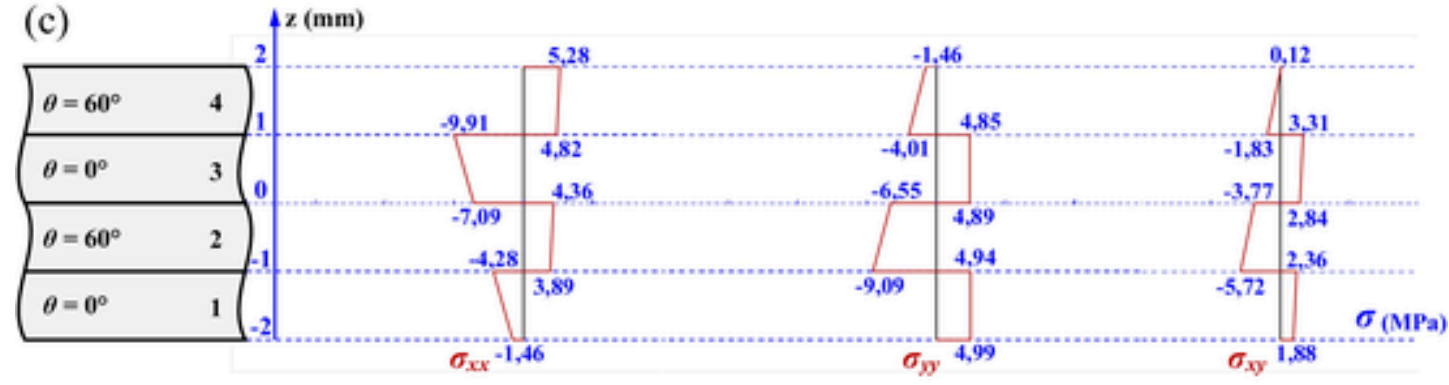

(d)

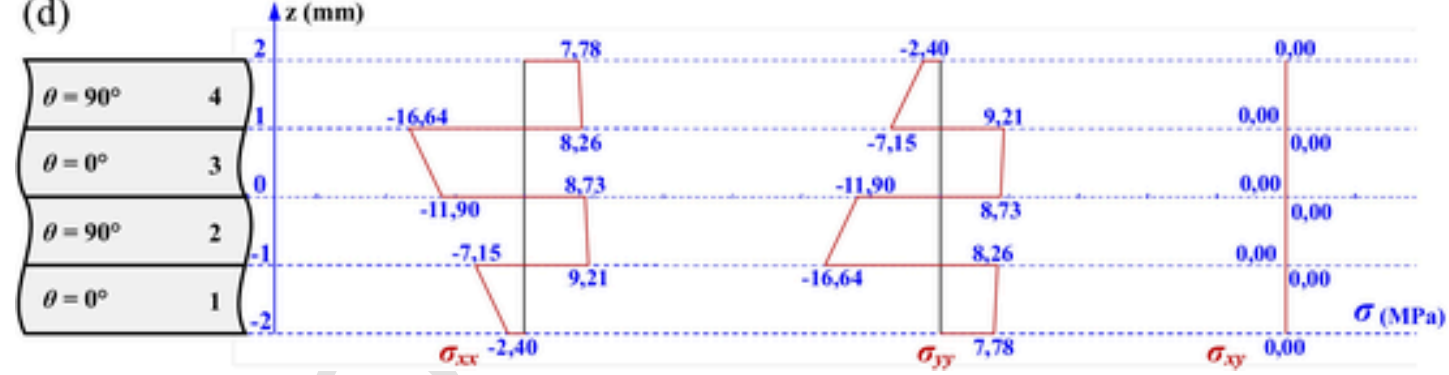

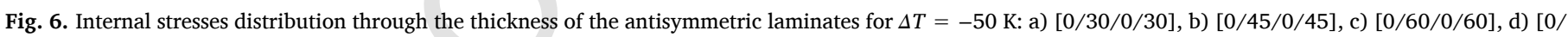
90/0/90].

\section{References}

Abida, M., Gehring, F., Mars, J., Vivet, A., Dammak, F., Haddar, M., 2019. Effect of hygroscopy on non-impregnated quasi-unidirectional flax reinforcement behaviour. Ind. Crops Prod. 128, 315-322. https://doi.org/10.1016/j.indcrop.2018.11.008.

Amiri, A., Triplett, Z., Moreira, A., Brezinka, N., Alcock, M., Ulven, C.A., 2017. Standard density measurement method development for flax fiber. Ind. Crops Prod. 96, 196-202. https://doi.org/10.1016/j.indcrop.2016.11.060.

Asghari, B., Ghasemi, A.R., Tabatabaeian, A., 2019. On the optimal design of manufacturing-induced residual stresses in filament wound carbon fiber composite cylindrical shells reinforced with carbon nanotubes. Compos. Sci. Technol. 182, 107743. https://doi.org/10.1016/j.compscitech.2019.107743.

ASTM D6341-16, 2016. Standard Test Method for Determination of the Linear Coefficient of Thermal Expansion of Plastic Lumber and Plastic Lumber Shapes Between -30 and $140^{\circ} \mathrm{F}\left(-34.4\right.$ and $\left.60^{\circ} \mathrm{C}\right)$, ASTM International, West Conshohocken, PA. www.astm.org, doi:10.1520/D6341-16.

ASTM E831-06, 2006. Standard Test Method for Linear Thermal Expansion of Solid Materials by Thermomechanical Analysis, ASTM International, West Conshohocken, PA. www.astm.org, doi:10.1520/E0831-06.

Baley, C., Bourmaud, A., 2014. Average tensile properties of French elementary flax fibers. Mater. Lett. 122, 159-161. https://doi.org/10.1016/j.matlet.2014.02.030. Baley, C., Kervoëlen, A., Le Duigou, A., Goudenhooft, C., Bourmaud, A., 2016. Is the low shear modulus of flax fibres an advantage for polymer reinforcement?. Mater. Lett. 185, 534-536. https://doi.org/10.1016/j.matlet.2016.09.067.

Baley, C., Bourmaud, A., Davies, P., 2021. Eighty years of composites reinforced by flax fibres: a historical review. Compos. Part A Appl. Sci. Manuf.. https://doi.org/10.1016/j. compositesa.2021.106333.

Cadu, T., Van Schoors, L., Sicot, O., Moscardelli, S., Divet, L., Fontaine, S., 2019. Cyclic hygrothermal ageing of flax fibers' bundles and unidirectional flax/epoxy composite. Are bio-based reinforced composites so sensitive?. Ind. Crops Prod. 141. https://doi.org/ 10.1016/j.indcrop.2019.111730.

Chamis, C.C., 1983. Simplified composite micromechanics equations for hygral, thermal and mechamcal properties. In: 38th Annual Conference of the Society of the Plastics Industry Reinforced Plastics/Composites Institute. Houston, Texas; United States. pp. 7-11.

Chilali, A., Assarar, M., Zouari, W., Kebir, H., Ayad, R., 2018a. Analysis of the hydromechanical behaviour of flax fibre-reinforced composites: Assessment of hygroscopic expansion and its impact on internal stress. Compos. Struct. 206, 177-184. https://doi. org/10.1016/j.compstruct.2018.08.037.

Chilali, A., Zouari, W., Assarar, M., Kebir, H., Ayad, R., 2018b. Effect of water ageing on the load-unload cyclic behaviour of flax fibre-reinforced thermoplastic and 
thermosetting composites. Compos. Struct. 183, 309-319. https://doi.org/10.1016/J. COMPSTRUCT.2017.03.077.

Cichocki, F.R., Thomason, J.L., 2002. Thermoelastic anisotropy of a natural fiber. Compos. Sci. Technol. 62, 669-678. https://doi.org/10.1016/S0266-3538(02)00011-8. Dai, J., Xi, S., Li, D., 2019. Numerical analysis of curing residual stress and deformation in thermosetting composite laminates with comparison between different constitutive models. Materials (Basel) 12. https://doi.org/10.3390/ma12040572.

Djellouli, B., Zouari, W., Assarar, M., Ayad, R., 2021. Analysis of the hygroscopic and hygroelastic behaviours of water aged flax-epoxy composite. Compos. Struct. 265, 113692. https://doi.org/10.1016/j.compstruct.2021.113692.

Gager, V., Le Duigou, A., Bourmaud, A., Pierre, F., Behlouli, K., Baley, C., 2019. Understanding the effect of moisture variation on the hygromechanical properties of porosity-controlled nonwoven biocomposites. Polym. Test. 78, 105944. https://doi.org/ 10.1016/j.polymertesting.2019.105944.

Gentles, F., Anderson, J., Thomason, J.L., 2010. Characterisation of the transverse thermoelastic properties of natural fibres used in composites. In: 14th European Conference on Composite Materials, ECCM14. Budapest, Hungary. pp. 7-10.

Gon, D., Das, K., Paul, P., Maity, S., 2012. Jute composites as wood substitute. Int. J. Text. Sci. 1, 84-93. https://doi.org/10.5923/j.textile.20120106.05.

Gong, X.L., Wen, Z., Su, Y., 2015. Experimental determination of residual stresses in composite laminates [02/ 02$]$ s. Adv. Compos. Mater. 24, 33-47. https://doi.org/10. $1080 / 09243046.2014 .937136$.

Goudenhooft, C., Bourmaud, A., Baley, C., 2017. Varietal selection of flax over time: evolution of plant architecture related to influence on the mechanical properties of fibers. Ind. Crops Prod. 97, 56-64. https://doi.org/10.1016/j.indcrop.2016.11.062. Karadeniz, Z.H., Kumlutas, D., 2007. A numerical study on the coefficients of thermal expansion of fiber reinforced composite materials. Compos. Struct. 78, 1-10. https://doi. org/10.1016/j.compstruct.2005.11.034.

Karthi, N., Kumaresan, K., Sathish, S., Gokulkumar, S., Prabhu, L., Vigneshkumar, N., 2019. An overview: natural fiber reinforced hybrid composites, chemical treatments and application areas. In: Materials Today: Proceedings. Elsevier Ltd. pp. 2828-2834. https://doi.org/10.1016/j.matpr.2020.01.011.

Kim, Y.K., Chalivendra, V., 2020. Natural fibre composites (NFCs) for construction and automotive industries. Handbook of Natural Fibres: Volume 2: Processing and Applications. Elsevier Inc., pp. 469-498. https://doi.org/10.1016/B978-0-12-818782-1. 00014-6.

Le Duigou, A., Merotte, J., Bourmaud, A., Davies, P., Belhouli, K., Baley, C., 2017. Hygroscopic expansion: a key point to describe natural fibre/polymer matrix interface bond strength. Compos. Sci. Technol. 151, 228-233. https://doi.org/10.1016/j. compscitech.2017.08.028.

Lefeuvre, A., Bourmaud, A., Lebrun, L., Morvan, C., Baley, C., 2013. A study of the yearly reproducibility of flax fiber tensile properties. Ind. Crops Prod. 50, 400-407. https://doi. org/10.1016/j.indcrop.2013.07.035.

Madhu, P., Sanjay, M.R., Senthamaraikannan, P., Pradeep, S., Saravanakumar, S.S., Yogesha, B., 2019. A review on synthesis and characterization of commercially available natural fibers: Part-I. J. Nat. fibers 16, 1132-1144.

Magnier, A., Wu, T., Tinkloh, S.R., Tröster, T., Scholtes, B., Niendorf, T., 2021. On the reliability of residual stress measurements in unidirectional carbon fibre reinforced epoxy composites. Polym. Test. 97, 107146. https://doi.org/10.1016/j.polymertesting. 2021.107146.

Parlevliet, P.P., Bersee, H.E.N., Beukers, A., 2006. Residual stresses in thermoplastic composites - a study of the literature-Part I: formation of residual stresses. Compos. Part A Appl. Sci. Manuf.. https://doi.org/10.1016/j.compositesa.2005.12.025.

Parlevliet, P.P., Bersee, H.E.N., Beukers, A., 2007a. Residual stresses in thermoplastic composites - a study of the literature-Part II: experimental techniques. Compos. Part A Appl. Sci. Manuf.. https://doi.org/10.1016/j.compositesa.2006.07.002.

Parlevliet, P.P., Bersee, H.E.N., Beukers, A., 2007b. Residual stresses in thermoplastic composites - a study of the literature. Part III: effects of thermal residual stresses. Compos. Part A Appl. Sci. Manuf. 38, 1581-1596. https://doi.org/10.1016/j compositesa.2006.12.005.

Péron, M., Célino, A., Castro, M., Jacquemin, F., Le Duigou, A., 2019. Study of hygroscopic stresses in asymmetric biocomposite laminates. Compos. Sci. Technol. 169, 7-15. https://doi.org/10.1016/j.compscitech.2018.10.027.

Péron, M., Célino, A., Jacquemin, F., Le Duigou, A., 2020. Hygroscopic stresses in asymmetric biocomposite laminates submitted to various relative humidity conditions. Compos. Part A Appl. Sci. Manuf. 134, 105896. https://doi.org/10.1016/j.compositesa. 2020.105896

Pomel, C., 2003. Contribution à l'étude de matériaux composites renforcés par des fibres de lin. Université de Nantes.

Ramesh, M., Palanikumar, K., Reddy, K.H., 2017. Plant fibre based bio-composites: sustainable and renewable green materials. Renew. Sustain. Energy Rev. 79, 558-584. https://doi.org/10.1016/j.rser.2017.05.094.

Rojstaczer, S., Cohn, D., Marom, G., 1985. Thermal expansion of Kevlar fibres and composites. J. Mater. Sci. Lett. 4, 1233-1236. https://doi.org/10.1007/BF00723467.

Saidane, E., Scida, D., Assarar, M., Ayad, R., 2016a. Assessment of 3D moisture diffusion parameters on flax/epoxy composites. Compos. Part A Appl. Sci. Manuf. 80, 53-60. https://doi.org/10.1016/J.COMPOSITESA.2015.10.008.

Saidane, E., Scida, D., Assarar, M., Sabhi, H., Ayad, R., 2016b. Hybridisation effect on diffusion kinetic and tensile mechanical behaviour of epoxy based flax-glass composites. Compos. Part A Appl. Sci. Manuf. 87, 153-160. https://doi.org/10.1016/j.compositesa. 2016.04.023.

Schapery, R.A., 1968. Thermal expansion coefficients of composite materials based on energy principles. J. Compos. Mater. 2, 380-404. https://doi.org/10.1177/ 002199836800200308.

Scida, D., Bourmaud, A., Baley, C., 2017. Influence of the scattering of flax fibres properties on flax/epoxy woven ply stiffness. Mater. Des. 122, 136-145. https://doi.org/ 10.1016/J.MATDES.2017.02.094.

Tezvergil, A., Lassila, L.V.J., Vallittu, P.K., 2003. The effect of fiber orientation on the thermal expansion coefficients of fiber-reinforced composites. Dent. Mater. 19, 471-477. https://doi.org/10.1016/S0109-5641(02)00092-1.

Van Schoors, L., Cadu, T., Moscardelli, S., Divet, L., Fontaine, S., Sicot, O., 2021. Why cyclic hygrothermal ageing modifies the transverse mechanical properties of a unidirectional epoxy-flax fibres composite?. Ind. Crops Prod. 164, 113341. https://doi. org/10.1016/j.indcrop.2021.113341. 